\title{
Critical Temperatures and Heating Times for Fruit Damage in Northern Highbush Blueberry
}

\author{
Fan-Hsuan Yang \\ Department of Horticulture, Agricultural and Life Sciences Building 4017, \\ Oregon State University, Corvallis, OR 97331 \\ David R. Bryla \\ U.S. Department of Agriculture, Agricultural Research Service, $3420 \mathrm{NW}$ \\ Orchard Avenue, Corvallis, OR 97330
}

\author{
Bernadine C. Strik \\ Department of Horticulture, Agricultural and Life Sciences Building 4017, \\ Oregon State University, Corvallis, OR 97331
}

Additional index words. evaporative cooling, fruit quality, heat stress, sprinkler irrigation, Vaccinium corymbosum

\begin{abstract}
Over-canopy sprinkler systems are used to cool northern highbush blueberry (Vaccinium corymbosum $\mathbf{L}$.) fields and maintain fruit quality in the northwestern United States, but more information is needed to determine exactly when cooling is needed. The objective of this study was to identify the critical temperatures for heat damage to berries and for effective evaporative cooling. An initial study conducted in western Oregon in a mature planting of late-season 'Elliott' blueberry revealed that heat damage was typically observed within 1 to 3 days after an extreme heat event. Fruit damage, including softening, shriveling, and necrosis, occurred during both green and blue stages of development and was found primarily on sun-exposed berries, which on hot, sunny days $\left(>35^{\circ} \mathrm{C}\right)$ were 7 to $11^{\circ} \mathrm{C}$ warmer than the ambient air temperature. A subsequent study was conducted to determine whether the critical temperature for heat damage differed between the green and blue fruit stages. In this case, 'Aurora' was compared with 'Elliott' blueberry. Berries were heated using a chamber-free convective unit and were exposed for up to 4 hours to berry temperatures of 42 , 44,46 , and $48{ }^{\circ} \mathrm{C}$. When the berries were green, significant damage was visible at each temperature within 1.5 to 2 hours in 'Aurora' and 3 to 3.5 hours in 'Elliott'. Damage of green berries increased with time and temperature, and after 4 hours, ranged from $17 \%$ to $59 \%$ of the total berry number in the cluster in 'Aurora' and $10 \%$ to $24 \%$ in 'Elliott'. Fruit damage at the blue stage was less than at the green stage and was only significant at 46 and $48^{\circ} \mathrm{C}$ (within 3.5 to 2 hours, respectively) in 'Aurora' and at $48^{\circ} \mathrm{C}$ (within 2 hours) in 'Elliott'. Wax and cutin layers thickened on the berries as they progressed from green to blue, which perhaps increased their tolerance to heat at later stages of development. Based on these results, northern highbush blueberry fields should be cooled at air temperatures $>32{ }^{\circ} \mathrm{C}$ during the green stages of fruit development and $>35^{\circ} \mathrm{C}$ during ripening.
\end{abstract}

Crop loss from heat damage is becoming a prevalent problem for many blueberry growers in the northwestern United States. The region, which includes Oregon and

Received for publication 29 July 2019. Accepted for publication 3 Sept. 2019.

Funds for this research were provided by the Oregon and Washington Blueberry Commissions and the U.S. Department of Agriculture (CRIS number 2072-21000-048-00D)

We thank Julie Tarara, Scott Orr, and Teresa Sawyer for helpful assistance.

Mention of trade names or commercial products in this publication is solely for the purpose of providing specific information and does not imply recommendation or endorsement by the U.S. Department of Agriculture. F.-H.Y. is a former Ph.D. student. Current address: Sierra Cascade Nursery, 10230 Santa Fe Drive, Ballico, CA 95303.

D.R.B. is the corresponding author. E-mail: david. bryla@usda.gov. highbush (a complex hybrid based largely on $V$. corymbosum and $V$. darrowii Camp.) and rabbiteye blueberry ( $V$. virgatum Ait.), both of which are typically grown in warmer climates, northern highbush cultivars tend to be poorly adapted to high temperatures. During hot weather, net photosynthesis declines considerably in northern highbush blueberry, and high leaf temperatures result in large increases in plant water use (Bryla, 2011; Hancock et al., 1992). When high temperatures coincide with fruiting, water and carbohydrates are diverted from the fruit to supply leaves and other vegetative components of the plant, resulting in small or shriveled berries, hastened fruit ripening, and a reduction in fruit quality and storage (Lobos and Hancock, 2015). Berries exposed to direct sunlight tend to be the most susceptible to heat damage. Unlike leaves that cool via transpiration, blueberries have very few stomata on their surface and, therefore, do not have an effective means of cooling (Konarska, 2015).

At the cellular level, high temperatures disrupt the thermal stability of membranes and proteins, causing ion leakage and inhibition of physiological processes associated with fruit development (Inaba and Crandall, 1988; Schrader et al., 2011; Yu et al., 2016). Like many fruit, blueberries possess inherent qualities such as a waxy cuticle that provides natural protection against heat damage. The cuticle consists of a polyester matrix or cutin layer and an epicuticular wax layer. The latter, often referred to as the "bloom," is deposited on and in the cutin matrix and contains long-chain alkanes, acids, alcohols, and esters (Gülz, 1994). Without the wax, blueberries are prone to infections by bacteria and fungi, physical damage, and water loss (Jenks and Ashworth, 1999; Riederer and Schreiber, 2001). Knowledge of the ultrastructure and thickness of the cuticle may help us to understand how to select and manage cultivars for increased resistance to heat damage. Apart from transpiration, the cuticle protects the berries against sunburn resulting from exposure to ultraviolet radiation and excess heat absorption (Samuels et al., 2008; Shepherd and Griffiths, 2006).

Overhead sprinklers are sometimes used to cool blueberry fields during hot temperatures. However, most new blueberry fields in northwestern United States are irrigated by drip (Strik and Yarborough, 2005). Options for reducing heat damage with drip are currently limited. To contend with this problem, some growers install dual irrigation systems and use microsprinklers to cool the berries and use drip tubing to irrigate the plants. These dual systems are similar to those used in apple [Malus $\times$ sylvestris (L.) Mill. var. domestica (Borkh.) Mansf.], where cooling not only prevents heat damage but also improves fruit size and color (Gindaba and Wand, 2005; Iglesias et al., 2002). The microsprinklers are located above the canopy and produce fine droplets of water that evaporate quickly. 

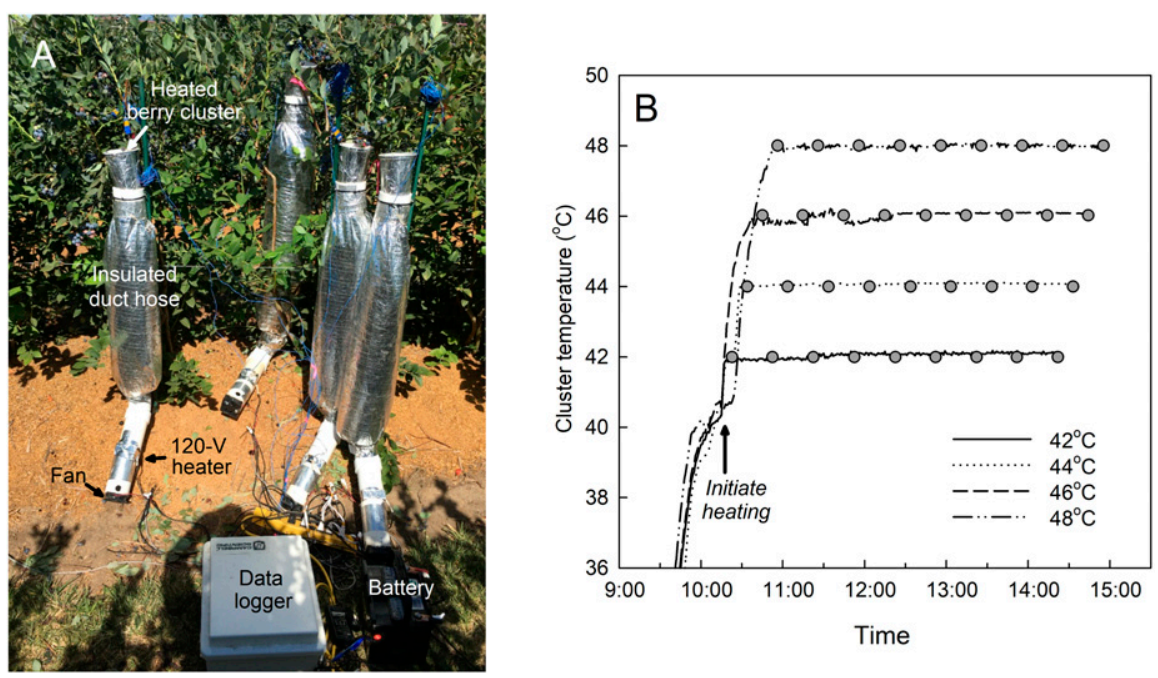

Fig. 1. (A) Forced convection units for heating clusters of berries in a mature planting of 'Aurora' and 'Elliott' blueberry. Each unit was controlled with a data logger and included a fan, heater, and insulated duct hose. (B) Surface temperature of the berries were heated for $4 \mathrm{~h}$ in the heating units. Heating was initiated between 0930 and $1030 \mathrm{HR}$ and maintained at 42, 44, 46, or $48{ }^{\circ} \mathrm{C}(\mathrm{n}=9)$. Gray circles indicate the time at which the berries were evaluated for heat damage.
Currently, there are many questions regarding the use of microsprinklers to reduce heat damage in northern highbush blueberry, including the temperature at which cooling is needed. Most growers focus their efforts on the later stages of berry development and initiate cooling whenever air temperature is expected to exceed 30 to $32{ }^{\circ} \mathrm{C}$ (F.-H. Yang, personal observation). However, there is no scientific basis for this decision, nor is there any information on how frequently the system should be run for cooling. Some growers run their microsprinklers continuously in hot weather, while others cycle them on for 15 to 30 min every hour.

The objective of the present study was to characterize and determine the critical temperatures and heating times for fruit damage in northern highbush blueberry. We also examined the ultrastructure of the berry cuticle to consider whether resistance to heat damage could be a heritable function of the amount of wax on the fruit. Damage was evaluated in late-season cultivars during green and blue stages of berry development. Late-season cultivars ripen in late summer

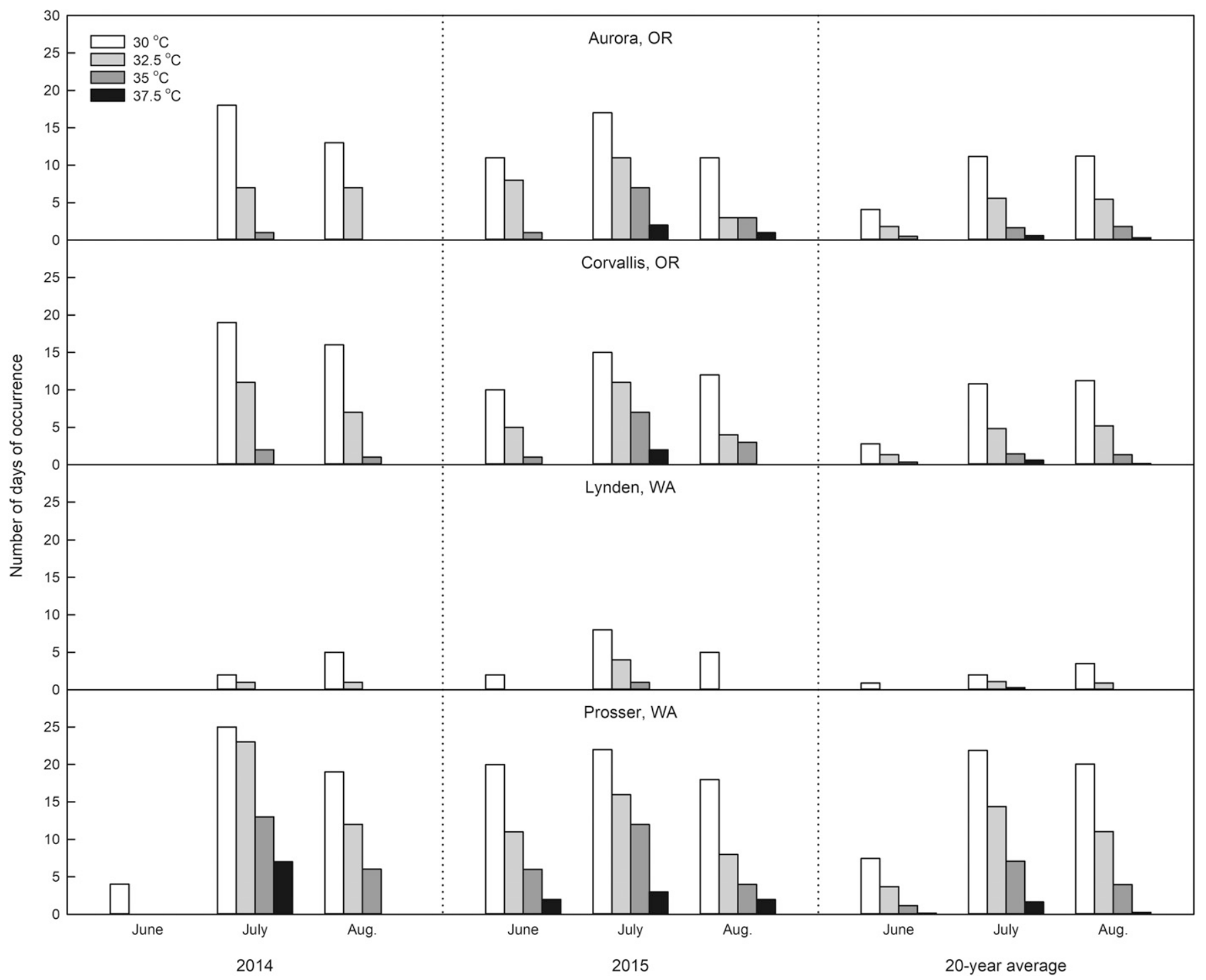

Fig. 2. Total number of days per month in which ambient air temperature exceeded $30,32.5,35$, and $37.5^{\circ} \mathrm{C}$ at four locations in Oregon and Washington. 
A

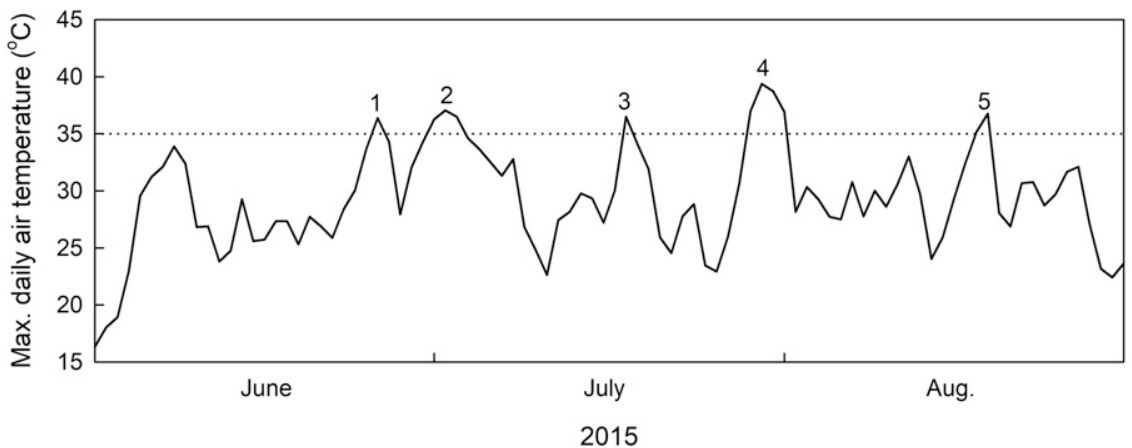

B

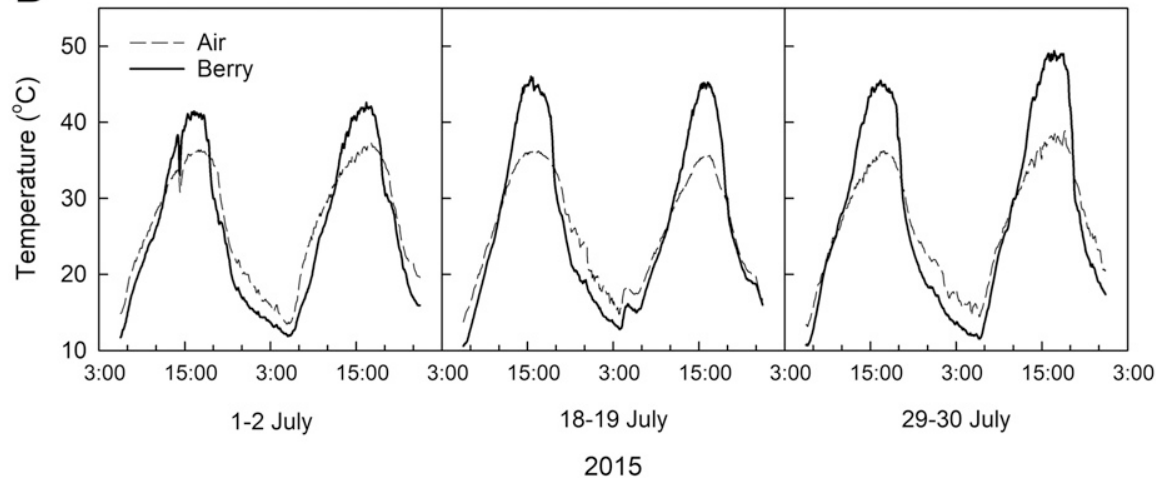

Fig. 3. (A) Maximum daily air temperatures during June to Aug. 2015 in Corvallis, OR. The numbers indicate five dates in which the temperature exceeded $35^{\circ} \mathrm{C}$ during the growing season. (B) Diurnal changes in air and berry surface temperature in a field of 'Elliott' blueberry during three extreme heat events (air temperature $>35^{\circ} \mathrm{C}$ ) in July $2015(\mathrm{n}=3)$.

when temperatures are warmer and, therefore, are often vulnerable to heat damage.

\section{Materials and Methods}

Weather conditions. Precipitation and maximum daily temperature readings were downloaded from AgriMet weather stations (https://www.usbr.gov/pn/agrimet) in Oregon and AgWeatherNet stations (https:// weather.wsu.edu) in Washington. Stations were selected from four primary regions for blueberry production in the Pacific Northwest, including near the cities of Aurora and Corvallis, which are located in northern and southern parts of the Willamette Valley in western Oregon, respectively, and near the cities of Lynden and Prosser in northwest and eastern Washington, respectively. Each station has been operational for more than 20 years.

Characterization of heat damage. Heat damage and diurnal changes in berry temperature were monitored during 2013-15 in a mature, 0.6-ha planting of 'Duke' and 'Elliott' blueberry. There was no evidence of heat damage in 'Duke', and therefore, only 'Elliott' was used in the present study. 'Elliott' is a late-season cultivar that ripens in August in western Oregon. The planting was established in Apr. 2004 at the Oregon State University Lewis-Brown Horticulture Research Farm in Corvallis, OR (lat. 44 33' $\mathrm{N}$, long. $123^{\circ} 13^{\prime} \mathrm{W}, 68 \mathrm{~m}$ elevation). The experimental plots used to assess heat dam- sured to compare the difference in temperature between the surface and center of the berries. To do so, in each measured cluster, four thermocouples were inserted beneath the skin of four berries, and for each of these berries, another thermocouple was inserted in the center of the berry. Ambient air temperature was also measured using a temperaturehumidity probe (HMP60; Vaisala, Woburn, WA). The probes were covered with a six-plate radiation shield (41303-5A; RM Young, Traverse City, MI) and mounted 1.8-m high. All thermocouples and air temperature data were collected every 5 min using data loggers (CR-1000; Campbell Scientific, Logan, UT)

Visual symptoms of heat damage were characterized by monitoring changes in the berries following warm weather events. Berries were also monitored for damage at commercial farms in Oregon and Washington. Heat damage usually occurred when air temperature exceeded $35^{\circ} \mathrm{C}$ and was proceeded by cooler weather conditions $\left(<25^{\circ} \mathrm{C}\right.$ the previous day).

Ultrastructure of the berry cuticle. Thickness of the cutin and epicuticular wax layers on the berries was examined using a scanning electron microscope (SEM) (Quanta 600F; FEI Company, Hillsboro, OR) with an acceleration voltage of $10 \mathrm{kV}$. Sun-exposed and shaded berries of 'Elliott' blueberry were collected randomly at the late green, pink, and $10 \%$ blue stages of development in 2014 . Samples were taken from eight plants at the site described above and included a total of eight clusters. To avoid removing the wax during sampling, each berry was held by inserting a dissection needle through the calyx. Skin was carefully removed from the equator of the berries using a razor blade. The skin was submerged immediately into a fixation solution $(2.5 \%$ glutaraldehyde, $1 \%$ paraformaldehyde in a $0.1 \mathrm{M}$ sodium cacodylate buffer) and was stored overnight at $5{ }^{\circ} \mathrm{C}$. The following day, skin samples were gradually washed and dehydrated with a series of $30 \%, 50 \%, 70 \%, 90 \%$, and $100 \%$ acetone. To maintain their cellular structure, we dried these using a $\mathrm{CO}_{2}$ critical point dryer (EMS 850; Electron Microscopy Sciences, Hatfield, PA). Once dried, the samples were frozen with liquid $\mathrm{N}$ and shattered into small specimens. The specimens were mounted onto aluminum stubs with doublesided carbon tape and coated with a $15-\mathrm{nm}$ thick layer of $60 \%$ gold and $40 \%$ palladium (Cressington 108 Auto Sputter Coater; Cressington, Watford, UK). Images of the specimens were captured at a magnification of $20645 \times$. Thickness of the cutin and epicuticular layers were measured at three random locations in each SEM image and averaged.

Data were analyzed within locations (sunexposed or shaded) by one-way ANOVA using R version 3.4.2 (R Core Team, 2017). Normality of the data was validated using the Shapiro-Wilk test, and homogeneity of variance was checked using Lavine's test. Means of berries collected at green and blue stages of development were separated using 

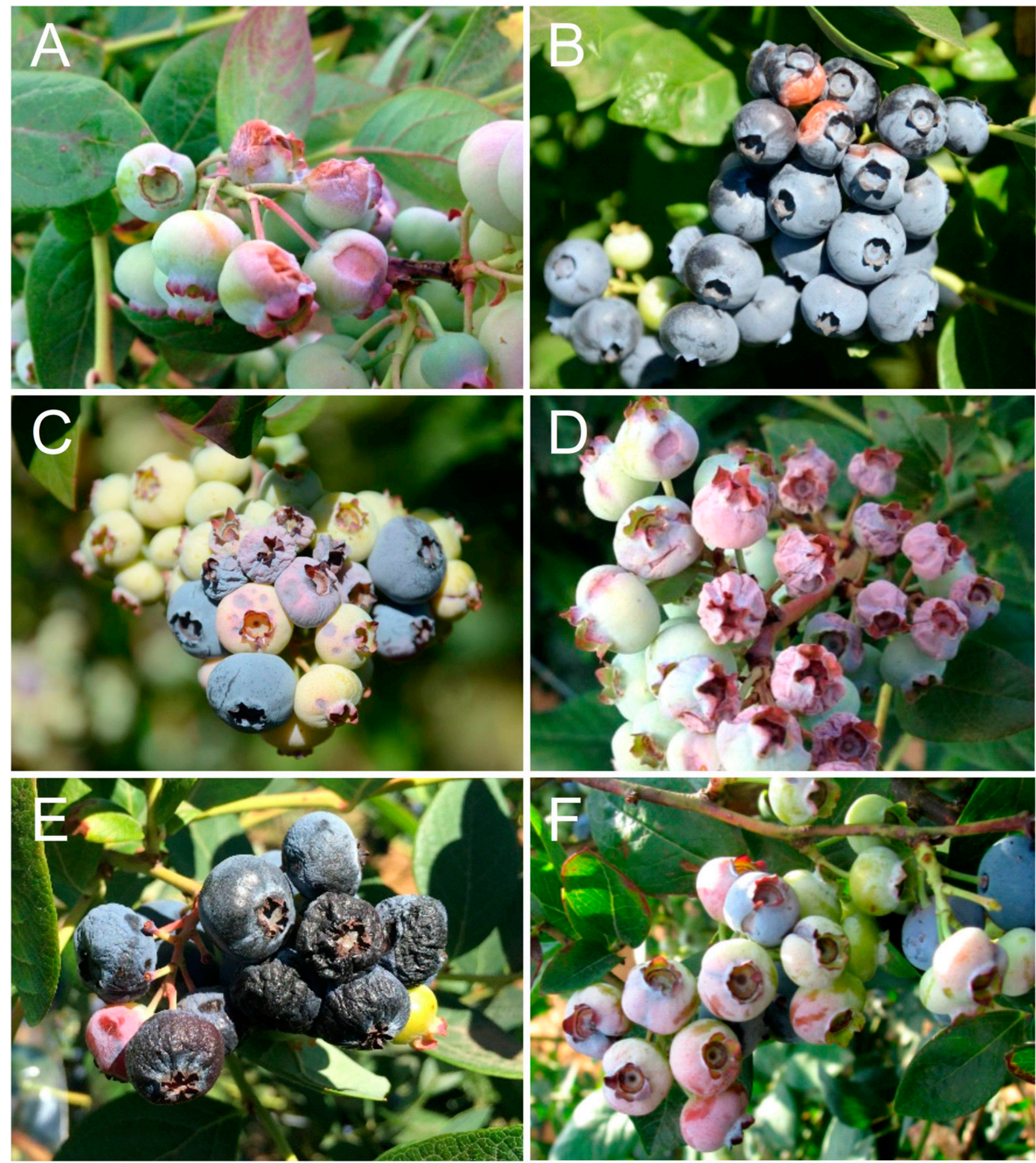

Fig. 4. Symptoms of heat damage in northern highbush blueberry include $(\mathbf{A}, \mathbf{B})$ necrosis, $(\mathbf{C})$ spotting, $(\mathbf{D}, \mathbf{E})$ shriveling or wrinkling, and $(\mathbf{F})$ poor coloration on the berries.

Tukey's honestly significant difference test $(\alpha=0.05)$. Means of sun-exposed and shaded berries were compared by paired $t$ test $(\alpha=$ $0.05)$.

Critical temperature and heating times for damage to the berries. Critical temperatures for heat damage were evaluated during 2016 in a 0.3 -ha planting of northern high- bush blueberry located at the Lewis-Brown Horticulture Research Farm. The planting was established in Oct. 2008 with six cultivars. Two late-season cultivars, Aurora and Elliott, were used in the present study. As in the previous experiment, plants were spaced $0.8 \times 3.0-\mathrm{m}$ apart on raised beds mulched with Douglas fir sawdust and were irrigated by drip. Refer to Vargas et al. (2015) for complete details on establishment of the planting.

Berry clusters were heated in situ for $4 \mathrm{~h}$ to a constant berry temperature of 42 , 44,46 , or $48^{\circ} \mathrm{C}$, and berry clusters without heat treatment were used as controls. These temperatures were chosen based on berry 


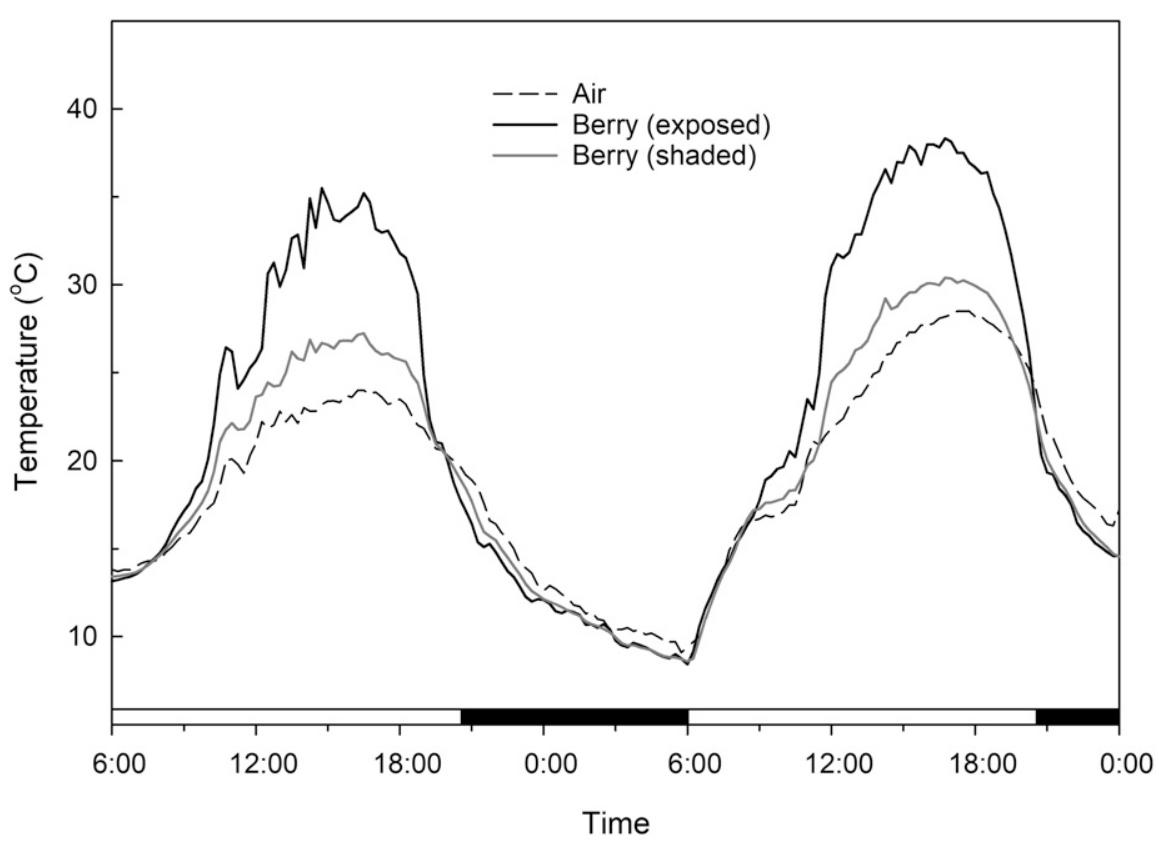

Fig. 5. Diurnal changes in air temperature and surface berry temperature of sun-exposed and shaded fruit of 'Elliott' blueberry. The measurements were taken on 2-3 Aug. 2013 in Corvallis, OR $(n=3)$. Dark regions on the $x$-axis indicate night.

temperatures observed in the field in 2015 (see below) and preliminary observations of heat damage in the laboratory (data not shown). Each treatment was replicated on three plants and repeated on three different warm, sunny days $\left(>32{ }^{\circ} \mathrm{C}\right)$ in August. All clusters were located on the upper, west side of the canopy and included at least 12 berries each at late green and fully blue stages of development. Berries at the green stage were $\approx 50 \%$ to $90 \%$ smaller in diameter than those at the blue stage. Heating was achieved by forced convection using a $120-\mathrm{V}$ heater (20055K111; McMaster-Carr, Los Angeles, CA) mounted to an axial fan (3110KL-04WB40; NMB Technologies, Chatsworth, CA) (Fig. 1A). Air flow was directed vertically to the clusters via insulated flexible duct hose (8.2-cm i.d.) supported on the ends by a $0.3-$ $\mathrm{m}$-long PVC pipe. Measurements of temperature in the cluster provided feedback at 5 -s intervals to control delivery of the heated air [see Tarara et al. (2000) for details]. Average berry temperature of the clusters was measured with thermocouples and a data logger, as described above, and the heaters were controlled by a relay power controller (SDM16AC; Campbell Scientific, Logan, UT). The percentage of berries with heat damage (discoloration) in a cluster were recorded every 30 min during heating (Fig. 1B).

The effect of cultivar, skin color, heating temperature, and time on the percent of berries with heat damage in the clusters was evaluated by ANOVA using R version 3.4.2. Due to the presence of three- and four-way interactions, the data were reanalyzed within each combination of cultivar and skin color. In each case, percent heat damage was significantly affected by the heating temperatures $(P<0.05)$. A pairwise $t$ test was performed at each temperature setting to determine whether means were different from the control (i.e., no heat damage) and to identify the time at which heat damage occurred within a given treatment.

\section{Results and Discussion}

Weather conditions. Temperature was cooler than normal in the spring and early summer of 2014. In June of that year, there was only one site where air temperature exceeded $30{ }^{\circ} \mathrm{C}$ (Fig. 2). However, by July, temperature was higher than normal and was $>35^{\circ} \mathrm{C}$ on 1 and $2 \mathrm{~d}$ in Aurora and Corvallis, OR, respectively, and on $13 \mathrm{~d}$ in Prosser, WA. Many fields in these three regions had soft and heat-damaged berries as a result of the warm weather (Peerbolt Crop Management, 2014). Fields in Lynden, WA, on the other hand, remained cool and had no heat damage.

The following year was warmer than normal. In 2015, temperature exceeded $35{ }^{\circ} \mathrm{C}$ by June in Aurora, Corvallis, and Prosser and by July in Lynden (Fig. 2). Heat damage was widespread and occurred in numerous cultivars throughout the region, including in Lynden. Damage to the berries was exacerbated by drought and water restrictions at several locations. Five extreme heat events were documented in Corvallis in 2015, including three in July (Fig. 3A). In each case, the temperature of sun-exposed berries was 7 to $11^{\circ} \mathrm{C}$ warmer than the air temperature (Fig. 3B). The hottest day was 30 July, which reached $38.9^{\circ} \mathrm{C}$. Berry temperatures peaked at $49^{\circ} \mathrm{C}$ on that date and were $>42{ }^{\circ} \mathrm{C}$ for nearly $4 \mathrm{~h}$. These temperatures are close to the thresholds for heat damage in other fruit crops, including apple (Schrader et al., 2011), pear (Pyrus communis L.) (McClymont et al., 2016), and pomegranate (Punica granatum L.) (Yazici and Kaynak, 2009).

The weather was also warmer than normal in 2016. In this case, temperature exceeded $35{ }^{\circ} \mathrm{C}$ by June in Aurora and Prosser and by July in Corvallis (data not shown). Heat damage was less extensive than the previous year but remained a considerable concern in the region.

Characterization of heat damage. Heat damage to the berries was typically observed within 1 to $3 \mathrm{~d}$ after an extreme heat event. The most prevalent symptom was necrosis or necrotic spots on the fruit (Fig. 4A and B). Necrosis occurred in both green- and bluecolored berries and usually happened on the upper portion of the fruit surface exposed to full sunlight. Browning and reddish spots often appeared before necrosis, and the skin then collapsed a few days later. Similar symptoms occur on sun-exposed apples (Schrader et al., 2011). A second type of heat damage was spotting on the berries (Fig. 4C). Spotting was like necrosis, but the damage was typically less extensive. Symptoms occurred during the late green stage of fruit development and manifested as purple spots on the surface of the fruit. In many cases, spotted berries continued to ripen but formed crevices within the spots. Spotting was usually found in berries that had partial leaf cover. Perhaps the spots were caused by light and heat transmitting through the space between the leaves. A third type of heat damage was shriveling or wrinkling (Fig. 4D and E). Like necrosis, shriveling occurred in both green- and blue-colored berries. The berries in this case began to dry, shrink, and appear raisin-like. Shriveling occurred as a result of severe damage at the pedicel end or on the entire berry. Krasnow et al. (2010) described the symptom as severe desiccation due to sun exposure in wine grapes (Vitis vinifera L.). At the blue stage of development, shriveling usually began with darkening on the fruit surface, followed by turgor loss and wrinkling a few days later. Darkening of the berries has also been reported in grapes and appears to be due to the degradation of surface crystalline wax (Bondada and Keller, 2012). The final type of heat damage observed was poor coloration during ripening (Fig. 4F). Berries with this type of damage tended to be smaller and less blue at maturity than other berries on the same cluster. Blueberries may also soften excessively during high temperature events. Soft berries are difficult to identify visually but are typically sorted out on the packing line.

In most cases, heat damage occurred in berries that were exposed to sunlight. Even on a relatively cool day $\left(<25^{\circ} \mathrm{C}\right)$, the temperature of berries in full sun was 11 to $12{ }^{\circ} \mathrm{C}$ warmer than the ambient air temperature, while the temperature of those in the shade was never more than 1 to $3{ }^{\circ} \mathrm{C}$ above ambient (Fig. 5). Others have demonstrated that fruit surface temperature is a function of advective 


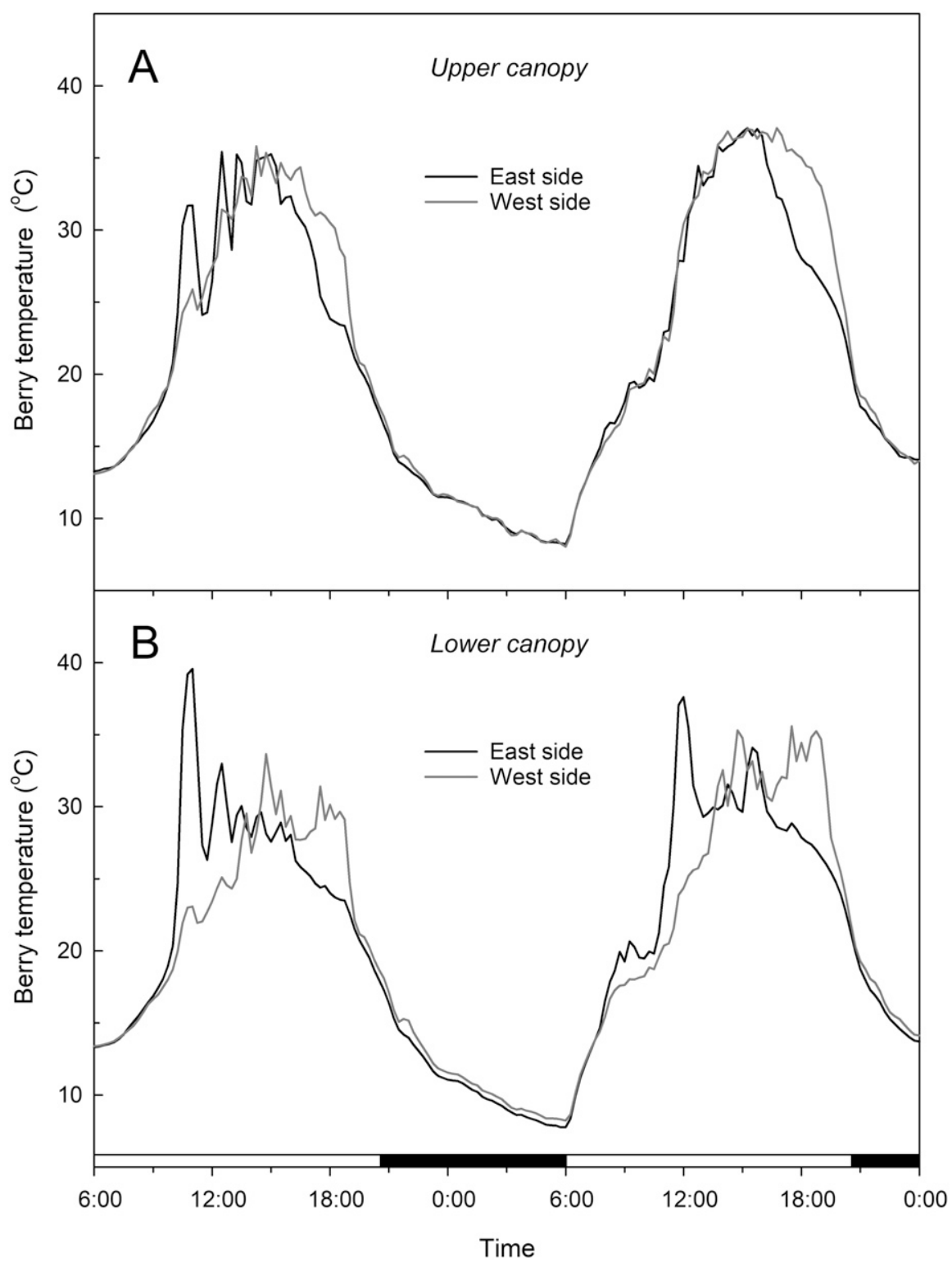

Fig. 6. Diurnal changes in surface temperature of berries located on the east and west side of the row in (A) upper and (B) lower parts of the canopy of 'Elliott' blueberry. The measurements were taken on 2-3 Aug. 2013 in Corvallis, OR $(n=3)$. Dark regions on the $x$-axis indicate night.

and solar heating and, therefore, is correlated to both air temperature and solar radiation (Schrader et al., 2003; Yazici and Kaynak, 2009).

The number of berries with heat damage on the plants was similar on both sides of the row but was typically greater in the upper than in the lower portion of the canopy (F.-H. Yang, personal observation). With rows running from north to south (the most common row arrangement), berries located on the east side of the row heated up sooner in the day than those on the west side, but they also cooled down earlier as the sun moved across the sky (Fig. 6A and B). As a result, total heat load was similar between the berries on both sides of the row. However, heat load was dissimilar between the upper and lower portions of the canopy. Berry temperature was cooler, on average, in the lower canopy and fluctuated more so than it did in the upper ture (Fig. 8). Evans (2004) suggested that development of red skin color may reduce albedo and increase heat load during ripening in apples. However, apples are much larger than blueberries and, therefore, have greater thermal capacity and much lower rates of heat dissipation.

Ultrastructure of the berry cuticle. The berries were covered with a well-defined layer of epicuticular wax and cuticle (Fig. 9A). The outer surface of the wax layer was primarily crystalline during the early stages of development (Fig. 9B) and later became amorphous as the berries turned pink and blue (Fig. 9C). Both the wax and cuticle layers thickened as the berries ripened (Fig. 9D and E). On average, these layers increased by $84 \%$ and $70 \%$, respectively, as the berries changed from green to blue (Fig. 9F and G). Konarska (2015) observed similar morphological changes on the fruit surface of 'Bluecrop' blueberries. It was estimated that the thickness of the wax layer in 'Bluecrop' increased by $45 \%$ and the cuticle layer increased by $47 \%$ between 35 (early green stage) and $70 \mathrm{~d}$ after anthesis (maturity).

The wax and cuticle layers were also thicker on sun-exposed berries than on shaded berries (Fig. 9F and G). Similar results have been found in grape (Rosenquist and Morrison, 1989). Wax accumulation may protect sun-exposed berries against heat and light damage. Epicuticular wax is well known to increase reflection of visible and ultraviolet light in plants (Holmes and Keiller, 2002; Shepherd and Griffiths, 2006). Due to its strong ultraviolet-absorbing capabilities, phenolic fatty-acid esters in the wax appear to play an important role in sunscald resistance in apple (Whitaker, 1998). Perhaps cultivars with thicker wax layers on the fruit are less susceptible to heat damage and could be selected for better adaptation to warmer climates. Differences in membrane chemistry or the presence of heat-shock proteins could also lead to differences in heat tolerance among cultivars. For example, $\beta$-diketones, which are the second most abundant compounds in the wax layer of blueberries (Chu et al., 2017), have been associated with heat-tolerance in wheat (Zhang et al., 2015). Heat shock proteins are also present in blueberry (Shi et al., 2017) and have been linked to heat tolerance in strawberry (Brown et al., 2016). Further research is warranted to determine whether the wax and cuticle layers could be manipulated with either breeding or management practices to increase resistance to heat damage in northern highbush blueberry.

Critical temperatures for heat damage. The time and temperature required to cause heat damage differed by cultivar and the stage of berry development. Overall, 'Aurora' was more susceptible to heat damage than 'Elliott', particularly when the berries were green. Damage was seen in green 'Aurora' berries within 1.5 to $2 \mathrm{~h}$ in each temperature treatment (Fig. 10A). A substantial percentage of these berries were damaged on the cluster after $4 \mathrm{~h}$ of heating, ranging from $17 \%$ to $59 \%$ at 42 to $48{ }^{\circ} \mathrm{C}$ at the berry surface. Green 'Elliott' berries, on the other hand, had much less damage than 'Aurora'. 


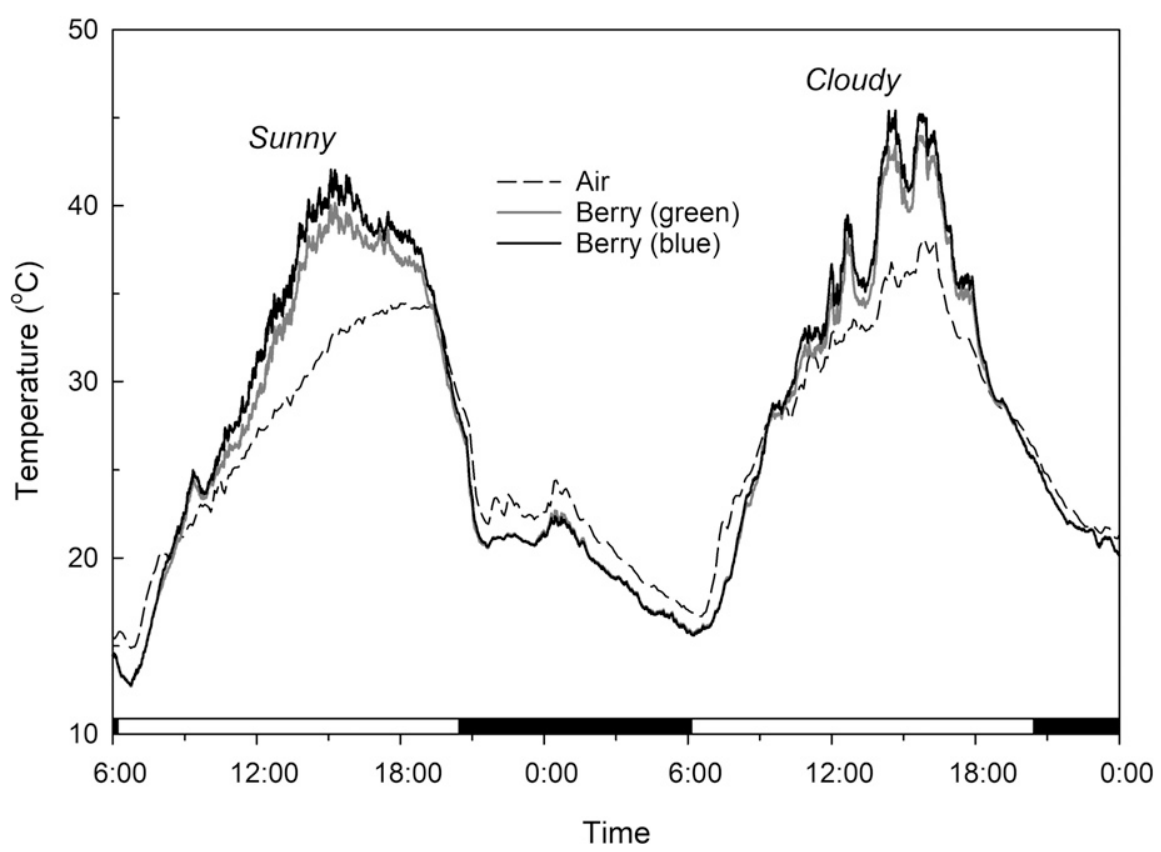

Fig. 7. Diurnal changes in air temperature and berry surface temperature of green and blue fruit of 'Elliott' blueberry. The measurements were taken on 10-11 Aug. 2014 in Corvallis, OR $(n=3)$. Dark regions on the $x$-axis indicate night.

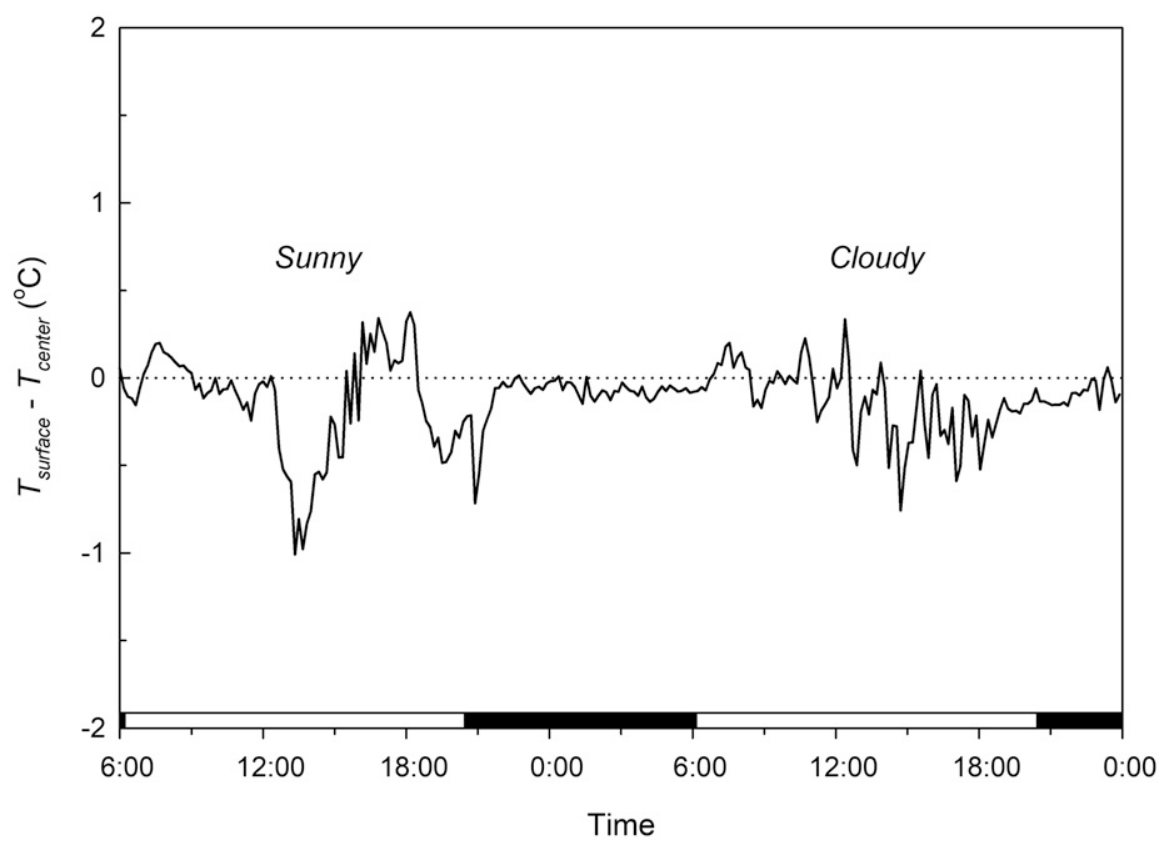

Fig. 8. Diurnal differences between the surface temperature $\left(T_{\text {surface }}\right)$ and the temperature at the center of the berry $\left(T_{\text {center }}\right)$ in 'Elliott' blueberry. The measurements were taken on 10-11 Aug. 2014 in Corvallis, OR $(\mathrm{n}=3)$. Dark regions on the $x$-axis indicate night.

In this case, the berries remained largely undamaged for at least $3 \mathrm{~h}$; and after $4 \mathrm{~h}$, damage was limited to $<15 \%$ at 42 to $46{ }^{\circ} \mathrm{C}$ and $23 \%$ at $48{ }^{\circ} \mathrm{C}$ (Fig. $10 \mathrm{~B}$ ). The damage appeared initially as orange spots on the berries in both cultivars. The spots eventually became necrotic and were like those observed previously as a result of natural heat damage (Fig. 4A).

Heat damage was also evident when the berries were blue (Fig. 10C and D). The damage at this stage began with darkening. berries were damaged significantly within $3.5 \mathrm{~h}$ at $46{ }^{\circ} \mathrm{C}$ and $2 \mathrm{~h}$ at $48{ }^{\circ} \mathrm{C}$ (Fig. 10C). Damage in this case increased to $19 \%$ and $30 \%$ of the total number on the cluster after $4 \mathrm{~h}$ at 46 and $48^{\circ} \mathrm{C}$, respectively. Conversely, blue 'Elliott' berries sustained minimal damage after $4 \mathrm{~h}$ at $46^{\circ} \mathrm{C}$ and had $<20 \%$ damage at $48^{\circ} \mathrm{C}$ (Fig. 10D). Significant damage at the latter temperature appeared within $2 \mathrm{~h}$ of heating.

\section{Conclusions}

Symptoms created artificially using forced convection units were very similar to those observed under natural field conditions, confirming that what is seen as "heat damage" in northern highbush blueberry is due primarily to high temperatures rather than ultraviolet radiation. Tolerance to heat appears to be primarily a function of cuticle thickness and less related to fruit color. Clearly, the berries were more tolerant to heat as the cuticle thickened during ripening. Thus, while temperatures are often warmer at later stages of berry development, the use of cooling practices is potentially more important when the berries are green. Depending on the cultivar, damage occurred in green berries within 2 to 3.5 hours at berry surface temperatures of 42 to $46{ }^{\circ} \mathrm{C}$ and 1.5 to $3 \mathrm{~h}$ at $48^{\circ} \mathrm{C}$. Berries at the blue stage, on the other hand, had little to no damage within 3 to 4 hours at 42 to $46{ }^{\circ} \mathrm{C}$. Heat damage occurred primarily on sun-exposed berries, which were 7 to $11^{\circ} \mathrm{C}$ warmer than air temperature on hot days. Thus, to avoid heat damage, northern highbush blueberry fields should be cooled at air temperatures $>32{ }^{\circ} \mathrm{C}$ during early stages of fruit development (green fruit) and $>35{ }^{\circ} \mathrm{C}$ during the later stages (mostly blue fruit)

Heat tolerance also differed between the two cultivars tested in the present study. We are uncertain why 'Aurora' was more susceptible to heat damage than 'Elliott', but the results suggest that tolerance to heat may be heritable and potentially selected for by breeding. If so, new cultivars could be developed not only to reduce heat damage at existing sites but also to extend the range of northern highbush blueberry to warmer and drier climates.

\section{Literature Cited}

Abatzoglou, J.T., D.E. Rupp, and P.W. Mote. 2014. Seasonal climate variability and change in the Pacific Northwest of the United States. J. Clim. 27:2125-2142.

Bondada, B. and M. Keller. 2012. Morphoanatomical symptomatology and osmotic behavior of grape berry shrivel. J. Amer. Soc. Hort. Sci. 137:20-30.

Brown, R., H. Wang, M. Dennis, J. Slovin, and W.W Turechek. 2016. The effects of heat treatment on the gene expression of several heat shock protein genes in two cultivars of strawberry. Intl. J. Fruit Sci. 16:239-248.

Bryla, D.R. 2011. Crop evapotranspiration and irrigation scheduling in blueberry, p. 167-186. In: G. Gerosa (ed.). Evapotranspiration-From 

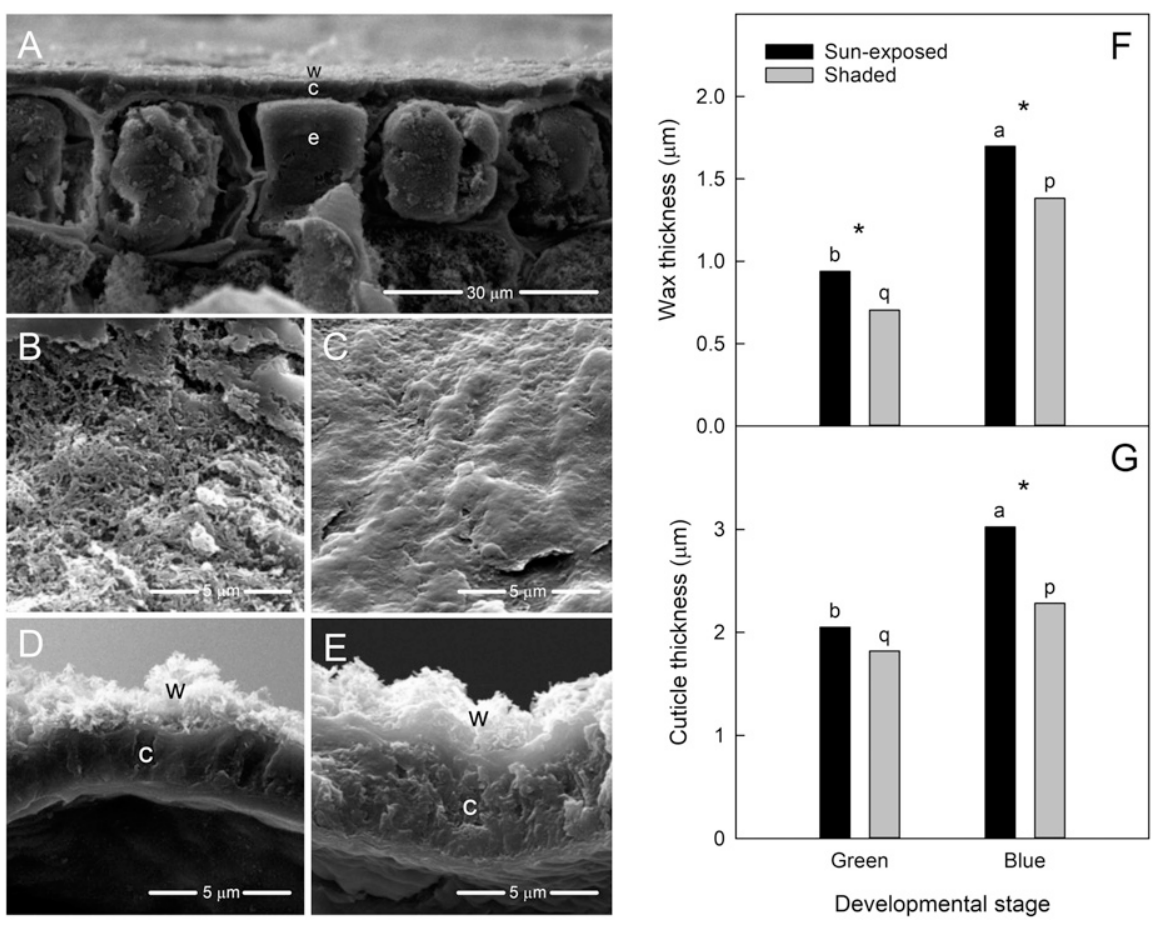

Fig. 9. SEM of 'Elliott' blueberry fruit: (A) cross-section of a berry at the early green stage; close-up of epicuticular wax on the surface of a berry at the (B) late green and (C) pink stage; and a close-up of the cutin layers at the (D) late green and $(\mathbf{E}) 10 \%$ blue stage. $\mathrm{w}=$ epicuticular wax; $\mathrm{c}=$ cuticle; and $\mathrm{e}=$ epidermal cell. Mean thickness of the $(\mathbf{F})$ cuticle and $(\mathbf{G})$ epicuticular wax layers on sun-exposed and shaded berries; the measurements were made at late green and $10 \%$ blue stages. Each bar represents the mean of eight replicates. Different letters above the bars indicate that means at green and blue stages of development were significantly different, according to Tukey's honestly significant difference test $(P \leq 0.05)$. Asterisks above the bars indicate that the means of sun-exposed and shaded berries at each stage were significantly different, according to paired $t$ tests $(P \leq 0.05)$.

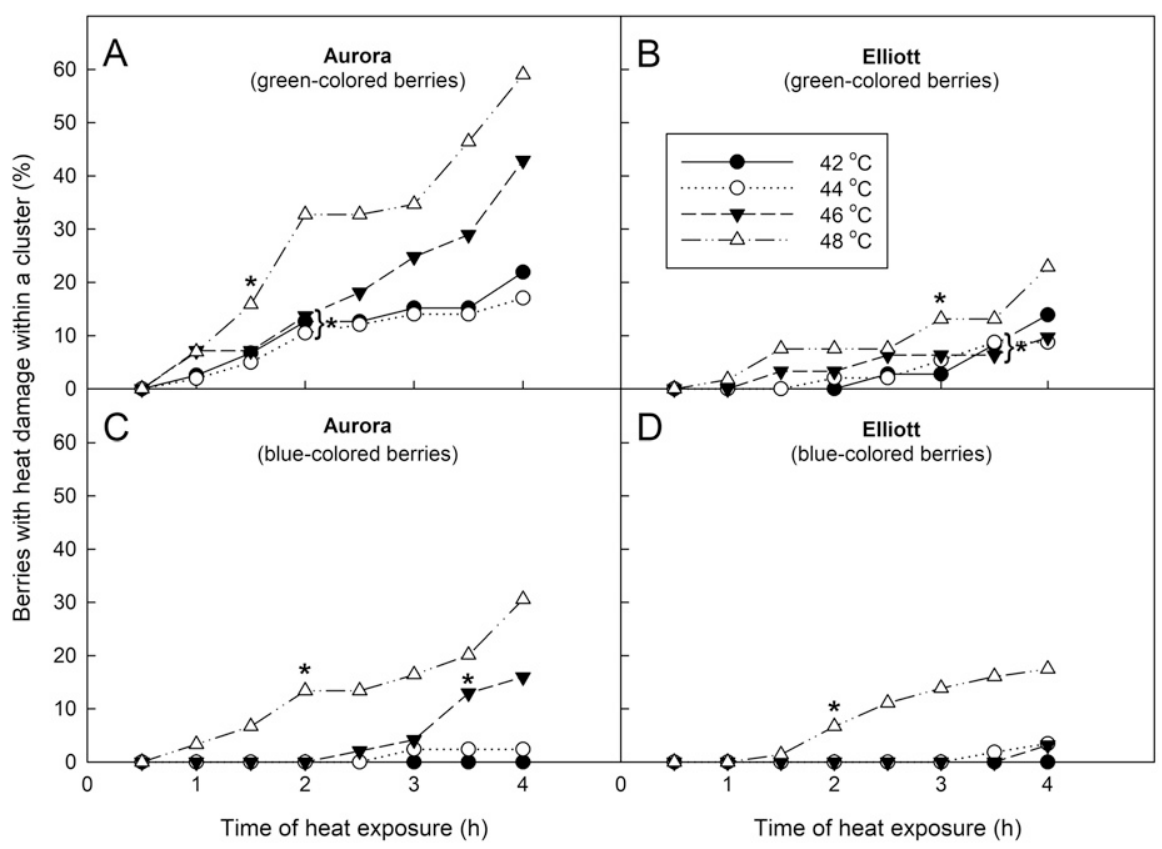

Fig. 10. Development of heat damage in green and blue fruit of 'Aurora' and 'Elliott' blueberry in Corvallis, OR in 2016. Clusters were heated for up to $4 \mathrm{~h}$ to average berry surface temperatures of 42 , 44,46 , or $48^{\circ} \mathrm{C}$ (see Fig. 1). Each symbol represents the mean of nine replicates. Asterisks indicate the time at which damage in a particular treatment was significantly different from the control (i.e., unheated clusters with no heat damage), according to pairwise $t$ tests $(P \leq 0.05)$.

measurements to agricultural and environmental applications. Intech, Rijeka, Croatia.

Bryla, D.R., J.L. Gartung, and B.C. Strik. 2011 Evaluation of irrigation methods for highbush
blueberry-I. Growth and water requirements of young plants. HortScience 46:95-101.

Chu, W., H. Gao, S. Cao, X. Fang, H. Chen, and S. Xiao. 2017. Composition and morphology of cuticular wax in blueberry (Vaccinium spp.) fruits. Food Chem. 219:436-442.

Evans, R.G. 2004. Energy balance of apples under evaporative cooling. Amer. Soc. Agr. Eng. 47:1029-1037.

Gindaba, J. and S.J.E. Wand. 2005. Comparative effects of evaporative cooling, kaolin particle film, and shade net on sunburn and fruit quality in apples. HortScience 40:592-596.

Gülz, P.-G. 1994. Epicuticular leaf waxes in the evolution of the plant kingdom. Plant Physiol. 143:453-464.

Hancock, J.F., K. Haghighi, S.L. Krebs, J.A. Flore, and A.D. Draper. 1992. Photosynthetic heat stability in highbush blueberries and the possibility of genetic improvement. HortScience 27:1111-1112.

Holmes, M.G. and D.R. Keiller. 2002. Effects of pubescence and waxes on the reflectance of leaves in the ultraviolet and photosynthetic wavebands: A comparison of a range of species. Plant Cell Environ. 25:85-93.

Houston, L., S. Capalbo, C. Seavert, M. Dalton, D. Bryla, and R. Sagili. 2018. Specialty fruit production in the Pacific Northwest: Adaptation strategies for a changing climate. Clim. Change 146:159-171.

Iglesias, I., J. Salvia, L. Torguet, and C. Cabús. 2002. Orchard cooling with overtree microsprinkler irrigation to improve fruit colour and quality of 'Topred Delicious' apples. Scientia Hort. 93:39-51.

Inaba, M. and P.G. Crandall. 1988. Electrolyte leakage as an indicator of high-temperature injury to harvested mature green tomatoes. J. Amer. Soc. Hort. Sci. 113:96-99.

Jenks, M.A. and E.N. Ashworth. 1999. Plant epicuticular waxes: Function, production, and genetics. Hort. Rev. 23:1-68.

Konarska, A. 2015. Morphological, anatomical, and ultrastructural changes in Vaccinium corymbosum fruits during ontogeny. Botany 93:589-602.

Krasnow, M., M. Matthews, R. Smith, J. Benz, E. Weber, and K. Shackel. 2010. Distinctive symptoms differentiate four common types of berry shrivel disorder in grape. Calif. Agr. 64:155-159.

Lobos, G.A. and J.F. Hancock. 2015. Breeding blueberries for a changing global environment: A review. Front. Plant Sci. 6:782, doi: 10.3389/ fpls.2015.00782.

McClymont, L., I. Goodwin, S. Turpin, and R. Darbyshire. 2016. Fruit surface temperature of red-blushed pear: Threshold for sunburn damage. N. Z. J. Crop Hortic. Sci. 44:262-273.

Peerbolt Crop Management. 2014. Small fruit update, 6 Aug. 2014. 12 Feb. 2017. $<$ http://www. nwberryfoundation.org/SFU/2014/32-SFU0806-14.pdf>.

R Core Team. 2017. R: A language and environment for statistical computing. R Foundation for Statistical Computing, Vienna, Austria. 2 Oct. 2017. <https://www.R-project.org>.

Riederer, M. and L. Schreiber. 2001. Protecting against water loss: Analysis of the barrier properties of plant cuticles. J. Expt. Bot. 52:2023-2032.

Rosenquist, J.K. and J.C. Morrison. 1989. Some factors affecting cuticle and wax accumulation on grape berries. Amer. J. Enol. Viticult. 40:241-244

Samuels, L., L. Kunst, and R. Jetter. 2008. Sealing plant surfaces: Cuticular wax formation by epidermal cells. Annu. Rev. Plant Biol. 59:683-707.

Schrader, L.E., J. Zhang, and W.K. Duplaga. 2011 Two types of sunburn in apple caused by high fruit surface (peel) temperature. Plant Health Prog., doi: 10.1094/PHP-2001-1004-01-RS.

Schrader, L., J. Zhang, and J. Sun. 2003. Environmental stresses that cause sunburn of apple. Acta Hort. 618:397-405. 
Schreiber, A. 2016. State of the Washington blueberryindustry. 26 Jan. 2017. <http://whatcom. wsu.edu/ag/edu/sfc/documents/sfc2015/Schreiber BlueComm_SFC2015.pdf $>$.

Shepherd, T. and D.W. Griffiths. 2006. The effects of stress on plant cuticular waxes. New Phytol. 171:469-499.

Shi, W., S. Su, B. Li, J. Yang, Z. Gong, and Z. Hou. 2017. Molecular characterisation and expression analysis of a sHsp gene involved in heat shock treatment-induced chilling tolerance in highbush blueberry fruit. J. Hort. Sci. Biotechnol. 92:455-464.

Strik, B.C. and D. Yarborough. 2005. Blueberry production trends in North America, 1992 to 2003 and predictions for growth. HortTechnology 15:391-398.
Tarara, J.M., J.C. Ferguson, and S.E. Spayd. 2000. A chamber-free method of heating and cooling grape clusters in the vineyard. Amer. J. Enol. Viticult. 51:182-188.

USDA. 2019. Noncitrus fruits and nuts. 2018 summary. 19 July 2019. <https://www.nass.usda. gov/Publications/Todays_Reports/reports/ ncit0619.pdf>.

Vargas, O.L., D.R. Bryla, J.E. Weiland, B.C. Strik, and L. Sun. 2015. Irrigation and fertigation with drip and alternative micro irrigation systems in northern highbush blueberry. HortScience 50:897-903.

Whitaker, B.D. 1998. Phenolic fatty-acid esters from the peel of 'Gala' apples and their possible role in resistance to superficial scald. Postharvest Biol. Technol. 13:1-10.
Yazici, K. and L. Kaynak. 2009. Effects of air temperature, relative humidity and solar radiation on fruit surface temperatures and sunburn damage in pomegranate (Punica granatum $\mathrm{L}$. cv. Hicaznar). Acta Hort. 818:181-186.

Yu, K., K. Zhu, M. Ye, Y. Zhao, W. Chen, and W. Guo. 2016. Heat tolerance of highbush blueberry is related to the antioxidative enzymes and oxidative protein-repairing enzymes. Scientia Hort. 198:36-43.

Zhang, Z., W. Wei, H. Zhu, G.S. Challa, C. Bi, H.N. Trick, and W. Li. 2015. W3 is a new wax locus that is essential for biosynthesis of $\beta$-diketone, development of glaucousness, and reduction of cuticle permeability in common wheat. PLoS One 10:e140524, doi: 10.1371/ journal.pone.0140524. 